\title{
Characterization of Oxide/Sulfide Molybdenum Hexagonal Rods
}

Carlos Ornelas $^{1}$, F. Paraguay-Delgado ${ }^{1}$, O. Solis-Canto ${ }^{1}$, W. Antunez-Flores ${ }^{2}$, K. Campos ${ }^{1}$ and J. LaraRomero $^{3}$

${ }^{1}$ Centro de Investigación en Materiales Avanzados (CIMAV), Laboratorio Nacional de Nanotecnología, Chihuahua, Chihuahua, Mexico, ${ }^{2}$ Hitachi, Chihuahua, Chihuahua, Mexico, ${ }^{3}$ Facultad de Ingeniería Química, Universidad Michoacana de San Nicolás de Hidalgo, Morelia, Michoacan de Ocampo, Mexico

Molybdenum sulfide $\left(\mathrm{MoS}_{2}\right)$ has been traditionally synthesized through different techniques, always the studies on structures and properties are focus on its applications. Different structures have been advantageous in several applications, due to its morphology or size like mono-layer, bulk or in support in hydrogen evolution reaction catalysis, hydrodesulfurization catalysts, electrochemical intercalation, hydrogen storage, elastic and coating materials in Li batteries and tribology [1]. The process of synthesis in $\mathrm{MoS}_{2}$ usually involves an insitu or ex-situ sulfurization process when the last one often is from an oxide molybdenum compound. Molybdenum oxide or any precursor to molybdenum sulfide has to pass to sulfurized form, this step is very important because it gives the final $\mathrm{MoS}_{2}$ compound and because the sulfurization process can modify the shape, morphology; and in consequences the properties of the material. In the past the purpose of sulfurization of structures was centered in the sulfurization from outside to the inside of the materials, usually, a partial sulfurization was explained to core-shell structures when in-side (core) was the non-sulfurized material and outside (shell) was the sulfurized material. This research brake whit this idea, and through XRD, TEM, and SEM characterization the sulfurization process in molybdenum oxide hexagonal bars was studied and investigated.

Molybdenum oxide $\left(\mathrm{MoO}_{3}\right)$ was synthesized by the microwave-assisted hydrothermal method according to the previous method reported by Paraguay-Delgado et al [2]. To obtain a molybdenum sulfide the $\mathrm{MoO}_{3}$ was sulfurized in a traditional process of sulfurized in a tubular furnace with $15 \% \mathrm{H}_{2} / \mathrm{H}_{2} \mathrm{~S}$ flow at $500^{\circ} \mathrm{C}$ for 4 hours. After the sulfurization process, the sample was characterized by XRD which shows a partial sulfurization, two phases were obtained hexagonal $\mathrm{MoS}_{2}$ and tetragonal $\mathrm{MoO}_{2}$. According to $\mathrm{XRD}$, the $\mathrm{MoS}_{2}$ phase is present with low stacking in (002) direction, it means small $\mathrm{MoS}_{2}$ crystals were formed and on the other hand, molybdenum not sulfurized presented a reduction from $\mathrm{MoO}_{3}$ to $\mathrm{MoO}_{2}$ and the signals show small crystals too. SEM results in Figure 1 show the hexagonal bars before and after the sulfurization process, the results show the same hexagonal morphology of the material in both cases, some grain forming hexagonal bars were founded in sulfurized one. To understand better the sulfurization process FIB preparation was done (figure 2 a)), figure $2 \mathrm{~b}$ ) shows an HRTEM Z-contrast image of transversal section obtained by FIB, it is clear than in micrometer diameter particles after sulfurization process, core-shell morphology was not obtained. All the morphologies were studied by HRTEM to understand how sulfur can make these morphologies, results showed a porous $\mathrm{MoS}_{2}$ structure (figure $2 \mathrm{c}-\mathrm{e}$ )) and small $\mathrm{MoO}_{2}$ Crystals covered by two or three $\mathrm{MoS}_{2}$ thin layers [3]. 


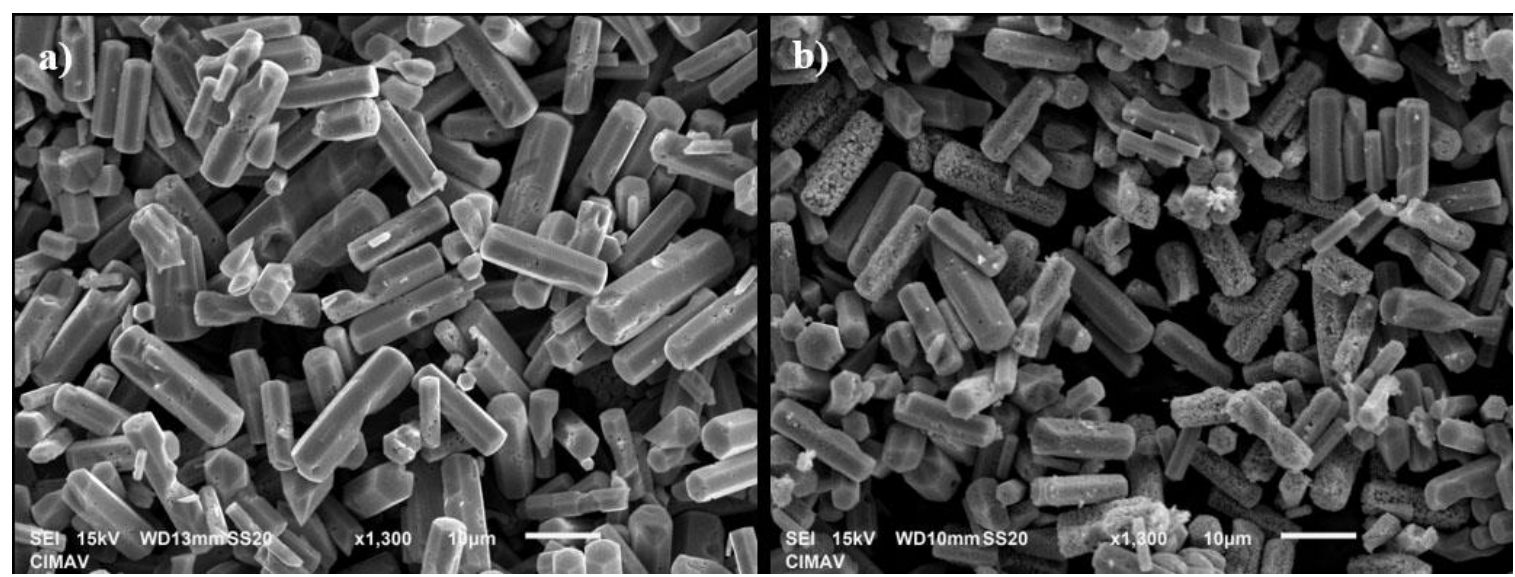

Figure 1. SEM Characterization a) Molybdenum oxide and b) Molybdenum oxide/sulfide
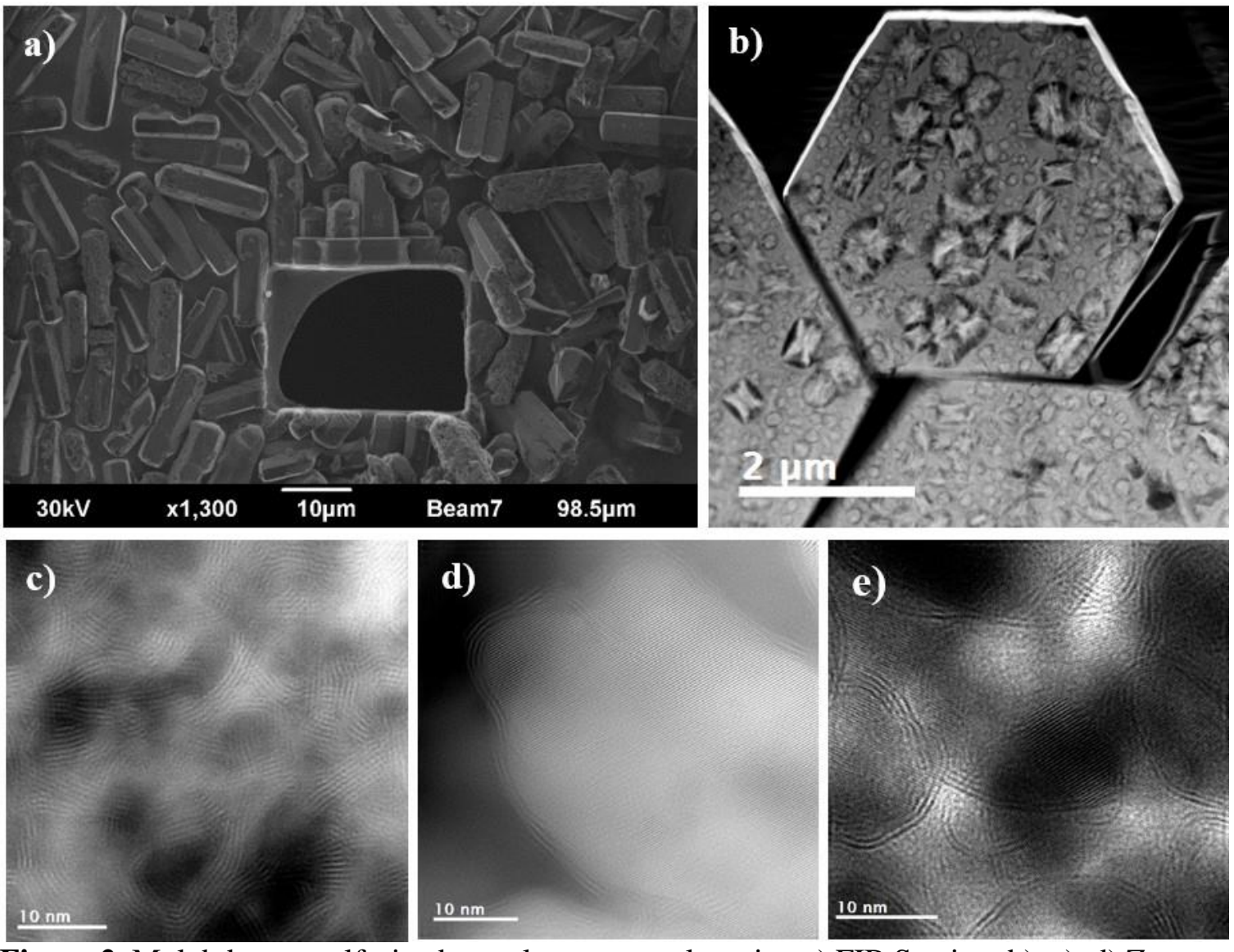

Figure 2. Molybdenum sulfurized sample transversal section a) FIB Section, b), c), d) Z contrast HRTEM and e) BF image HRTEM

\section{References}

[1] H. Zouli, Q Wenxiu, Applied Materials Today 3 (2016) p23-56.

[2] M. A. Albiter, R. Huirache-Acuña, F. Paraguay-Delgado, et al, Nanotechnology. 17, (2006) p3473-3481.

[3] Acknowledge to Ernesto Lestarjette for XRD assistance and Claudia Lopez for imagen processing. 